\title{
SOM230: A New Therapeutic Modality for Cushing's Disease
}

\author{
Ian Lewis $\S^{\star}$, Herbert A. Schmid, Rainer Kneuer, Daniel Hoyer, Antonio P. Silva, Gisbert Weckbecker, \\ Christian Bruns, and Janos Pless
}

§KGF-SCS Senior Industrial Investigator Award 2013

\begin{abstract}
A rational drug design approach involving transposition of functional groups from SRIF into a reduced size cyclohexapeptide template has led to the discovery of SOM230, a novel, stable cyclohexapeptide somatostatin mimic which exhibits unique high affinity binding to human somatostatin receptors (sst1-5). This unique receptor subtype binding profile, in particular the exceptional high affinity binding to sst5, led to SOM230 being approved by EMEA and FDA in 2012 as the first effective pituitary directed therapeutic modality for Cushing's disease.
\end{abstract}

Keywords: Cushing's disease $\cdot$ Medicinal chemistry $\cdot$ SOM230 $\cdot$ Somatostatin

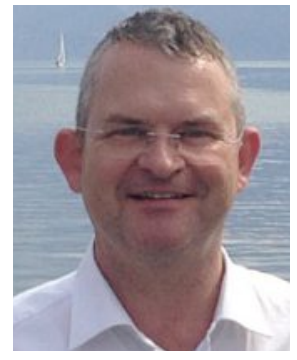

Ian Lewis studied for his $\mathrm{PhD}$ at the University of Edinburgh, under the supervision of Prof. R. Ramage from 1985 to 1988 . From 1988-90 he carried out research as a Royal

Society Postdoctoral Fellow in the group of Prof. A. Eschenmoser, ETH Zürich. In 1990 he joined the Novartis Institutes of Biomedical Research, Basel, undertaking research in the Endocrinology Department, Bone \& Joint Department, Core Technologies Combinatorial Chemistry Unit, Transplantation Chemistry Unit and Global Discovery Chemistry Exploratory Medicinal Chemistry Unit. In 2001/2002 he worked at the Scripps Research Institute, La Jolla, California as a Novartis Visiting Research Fellow with Prof. Dr. K. Barry Sharpless.
The somatostatin (SRIF, somatotropin release inhibiting factor) field has been a success story in terms of medicinal chemistry and drug discovery offering a variety of therapeutic opportunities exemplified in acromegaly, cancer, gastrointestinal disorders, whole body imaging and radiotherapy. The goal of this research programme was to determine if it would be therapeutically rewarding to design a full multi-receptor subtype binding SRIF mimic, instead of conventional subtype preferential agonists. Indeed, a rational medicinal chemistry approach capitalising on structure-activity relationships led to the discovery of SOM230, a novel, stable cyclohexapeptide somatostatin mimic which exhibits unique binding to human SRIF receptors (sst1-5).

This approach is based on transposing functional groups, in the form of unnatural non-proteolytically cleaved amino acids, from SRIF-14 into the stable, reduced size cyclohexapeptide template. Synthetic strategy was based on a solid phase approach using Fmoc/tBu strategy and the super-acid-sensitive SASRIN $^{\circledR}$ linker prior to cyclisation in solution after selective cleavage. Utilizing this strategy, the final structural optimisation of the cyclohexapeptide SRIF mimic was achieved by incorporating unique structural elements, adjusting the aromatic groups with the replacement of (L)-phenyl-alanine-2 ((L)-Phe-2) with (L)-phenylglycine-2 ((L)-Phg-2) in combination with (L)-tyrosine-benzyl-5 ((L)-Tyr(Bzl)-5) and the (S)-diaminoethylcarbamoyl-Pro-1 basic extension, decorating the exterior of the macrocyclic peptide and generating multi-receptor subtype binding SOM230. ${ }^{[1-6]}$ The influence of these unique structural elements on the $\beta$-turn and conformation of the SOM230 macrocycle ${ }^{[7]}$ are illustrat- ed in Fig. 1A-C. Furthermore, with the goal of enabling imaging and radiotherapy, the hydroxproline urethane extension of SOM230 has been functionalized with the chelators DTPA and DOTA, which allow early diagnosis and therapy of SRIF receptor-positive tumours. ${ }^{[6]}$ Uniquely, SOM230 exhibits binding with a 30 to 40 times higher affinity than Sandostatin ${ }^{\circledR}$ to the sst1 and sst5 receptors and exhibits higher efficacy in lowering growth hormone, ${ }^{[8]}$ and insulin-like growth factor-1 than Sandostatin ${ }^{\circledR}$.

In view of the physiological role of somatostatin in the regulation of pituitary function and the current use of somatostatin analogues in patients with anterior pituitary tumours, the potential of somatostatin analogues in patients with Cushing's disease has been explored. Cushing's disease is characterized by elevated levels of cortisol in the blood, arising from a tumour in the pituitary gland that stimulates excessive release of cortisol from the adrenal gland by releasing large amounts of ACTH. Patients presenting with Cushing's syndrome exhibit symptoms including rapid weight gain, particularly of the trunk and face, hypertension and insulin resistance leading to diabetes mellitus and ultimately heart disease and increased mortality. Despite this high unmet medical need, there has been, until now, no effective medical treatment for patients with pituitary-dependent Cushing's disease. Since SOM230 uniquely mimics the full pharmacological activity of naturally occurring somatostatin, it of fers potential as a new therapeutic modality for Cushing's disease. Recently, SOM230 has been shown to be much more effective than octreotide in inhibiting ACTH release by human and mouse corticotroph tumour cells in vitro. ${ }^{[9]}$ Clinical studies involving SOM230 treatment of pituitary-dependent 


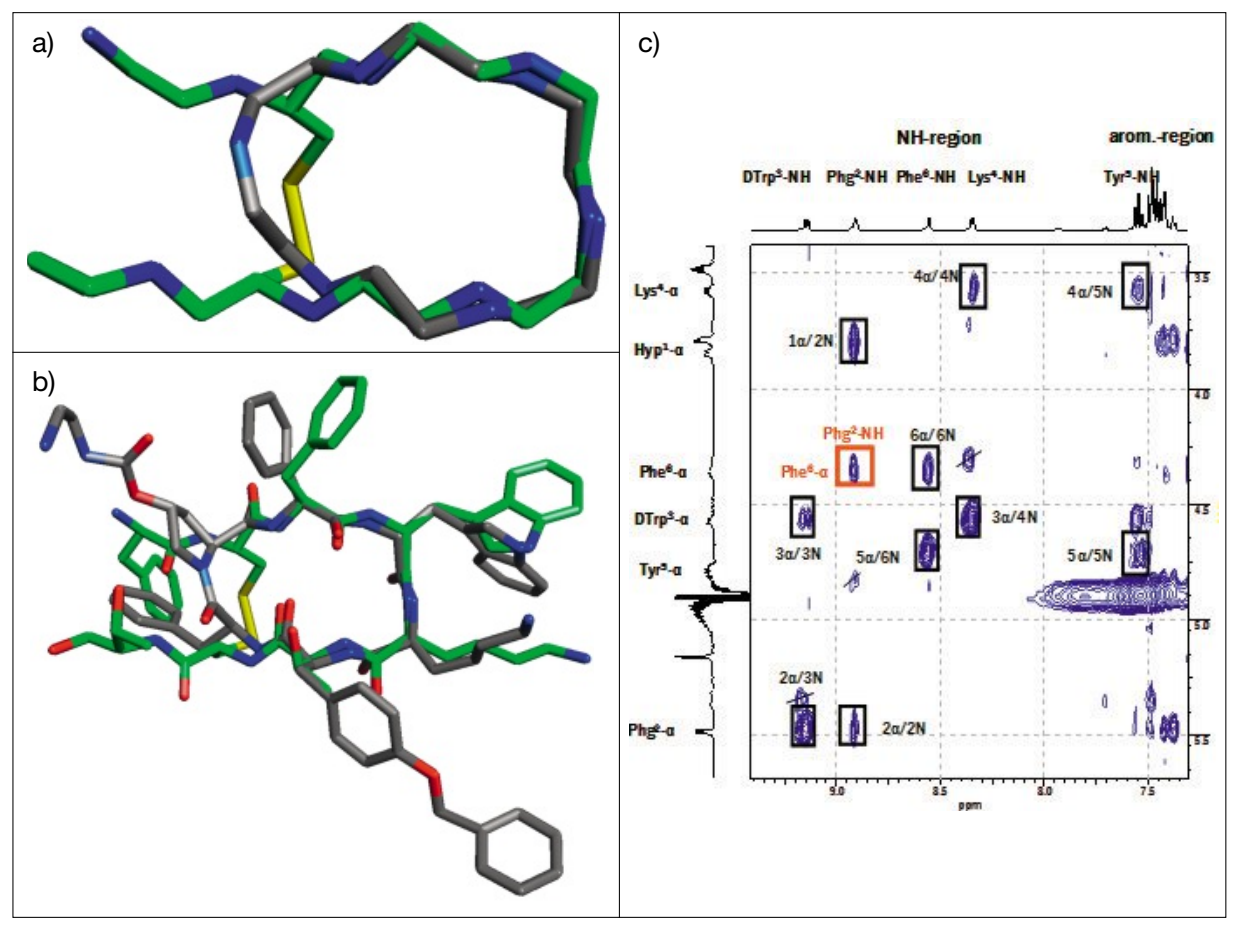

Fig. 1. a: $\beta$-Turn of SOM230 superimposed on $\beta$-turn of Sandostatin ${ }^{\circledR}$. b: Unnatural amino acids decorating the exterior of the SOM230 macrocyclic peptide: SOM230 superimposed on octreotide. c: NMR studies determining conformation of SOM230.

Cushing's disease, where a tumour in the pituitary gland stimulates excessive release of cortisol, have demonstrated that SOM230 produced a decrease in urinary free cortisol (UFC) levels in $76 \%$ of patients with Cushing's disease during the treatment period of 15 days, with direct effects on adrenocorticotropin release. These results demonstrated that SOM230 holds promise as the first effective pituitary directed therapeutic modality for Cushing's disease, ${ }^{[10-12]}$ which led to its approval by EMEA and FDA in 2012.

Received: July 18, 2014

[1] 'Rational approach to stable, universal somatostatin analogues with superior therapeutic potential', I. Lewis, W. Bauer, R. Albert, N. Chandramouli, J. Pless, G. Engel, G.
Weckbecker, C. Bruns, in 'Peptides: The Wave of the Future', Proc. $2^{\text {nd }}$ Int. and $17^{\text {th }} \mathrm{Am}$. Peptide Symp., San Diego, CA, United States, 2001, pp 716-718.

[2] 'SOM230: a novel somatostatin peptidomimetic with a broad somatotropin release inhibiting factor (SRIF) receptor binding and a unique antisecretory profile', C. Bruns, I. Lewis, U. Briner, G. Meno-Tetang, G. Weckbecker, Eur. J. Endocrinol. 2002, 146, 707.

[3] 'SOM230: a new somatostatin peptidomimetic with potent inhibitory effects on the growth hormone/insulin-like growth factor-I axis in rats, primates, and dogs', G. Weckbecker, U. Briner, I. Lewis, C. Bruns, Endocrinol. 2002, $143,4123$.

[4] 'A novel somatostatin mimic with broad SRIF receptor binding and superior therapeutic potential', I. Lewis, W. Bauer, R. Albert, N. Chandramouli, J. Pless, G. Weckbecker, C. Bruns, J. Med. Chem. 2003, 46, 2334.

[5] 'Opportunities in the somatostatin field: Biological, chemical and therapeutic aspects', G. Weckbecker, I. Lewis, R. Albert, H. Schmid,
D. Hoyer, C. Bruns, Nature Rev. Drug Discovery 2003, 2, 999.

[6] 'The superior therapeutic properties of SOM230 originate from unique structural elements', I. Lewis, R. Albert, W. Bauer, N. Chandramouli, J. Pless, L. Oberer, G. Bovermann, J. van der Hoek, V. Boerlin, S. W. J. Lamberts, H. A. Schmid, G. Weckbecker, C. Bruns, Chimia 2004, 58, 222.

[7] 'Unique structural elements profoundly influence the conformation of SOM230', L. Oberer, G. Interlandi, A. Caflisch, G. Bovermann, C. Ehrhardt, I. Lewis, in 'Peptide Revolution: Genomics, Proteomics \& Therapeutics', Eds. M. Chorev, T. K. Sawyer, American Peptide Society, 476, 2003.

[8] 'A single dose comparison of the acute effects between the new somatostatin analog SOM230 and octreotide in acromegalic patients', J. Van der Hoek, W. W. de Herder, R. A. Feelders, A. J. van der Lely, P. Uitterlinden, V. Boerlin, C. Bruns, K. W. Poon, I. Lewis, G. Weckbecker. T. Krahnke, L. J. Hofland, S. W. J. Lamberts, J. Clin. Endocrinol. Metab. 2004, 89, 638.

[9] 'The multi-ligand somatostatin analogue SOM230 inhibits ACTH secretion by cultured human corticotroph adenomas via somatostatin receptor type 5', L. J. Hofland, J. van der Hoek, R. Feelders, M. O. van Aken, P. M. van Koetsveld, M. Waaijers, D. Sprij-Mooij, C. Bruns, G. Weckbecker, Wouter W. de Herder, A. Beckers, S. W. J. Lamberts, Eur. J. Endocrinol. 2005, 152, 645 .

[10] 'Treatment of pituitary dependent Cushing's disease with the multi-receptor ligand somatostatin analog pasireotide (SOM230): A multicenter, phase II trial', M. Boscaro, W. H. Ludlam, B. Atkinson, J. E. Glusman, S. Petersenn, M. Reincke, P. Snyder, A. Tabarin, B. M.K. Biller, J. Findling, S. Melmed, C. H. Darby, K. Hu, Y. Wang, P. U. Freda, A. B. Grossman, L. A. Frohman, J. Bertherat, J. Clin. Endocrinol. Metab. 2009, 94, 115.

[11] 'A 12-Month Phase 3 Study of Pasireotide in Cushing's Disease', A. Colao, S. Petersenn, John Newell-Price, J. W. Findling, F. Gu, M. Maldonado, U. Schoenherr, D. Mills, L. R. Salgado, B. M. K. Biller, N. Engl. J. Med. 2012, $366,914$.

[12] 'Pasireotide Versus Octreotide in Acromegaly: A Head-to-Head Superiority Study', A. Colao, M. D. Bronstein, P. Freda, F. Gu, C.-C. Shen, M. Gadelha, M. Fleseriu, A. J. van der Lely, A. J. Farrall, K. Hermosillo Reséndiz, M. Ruffin, Y. Chen, M. Sheppard, on behalf of the Pasireotide C2305 Study Group, J. Clin. Endocrinol. Metab. 2014, 99, 791. 